\title{
Rancang Bangun Mesin Crawler di Instagram dan Pinterest untuk Kebutuhan Data pada Riset Visual
}

\author{
Halimatus Sa'dyah, Widi Sarinastiti, Reza R Ramadhan \\ Politeknik Elektronika Negeri Surabaya \\ Email : ${ }^{1}$ halimatus@pens.ac.id
}

\begin{abstract}
ABSTRAK
Media sosial memberikan bonus berupa data yang dapat dikelola menjadi informasi yang bermanfaat. Dalam penelitian ini, kami mengembangkan mesin crawler untuk media sosial Instagram dan Pinterest. Mesin crawler ini digunakan sebagai infrastruktur pendukung untuk mengambil data di media sosial. Data yang dihasilkan oleh mesin crawler selanjutnya digunakan sebagai bahan riset visual untuk merancang kemasan produk bagi konsumen menengah ke atas. Hasil uji coba menunjukkan bahwa penggunaan Apache MesOS dapat mempercepat proses crawling dari 30 jam menjadi 1 jam. Dalam hal seleksi data, pada Pinterest, mesin crawler ini dapat mencapai akurasi hingga 100\%. Sementara itu, pada Instagram, nilai Presisi tidak stabil dan berada pada rentang 34.8\% hingga 90.0\%. Sedangkan nilai recall dan akurasinya konsisten di bawah 70\%. Hal ini menunjukkan bahwa arsitekturr mesin crawler sudah sesuai untuk menyelesaikan permasalahan. Namun, perbaikan masih dibutuhkan dari sisi algoritma seleksi agar nilai Presisi, Recall dan Akurasi pada Instagram dapat ditingkatkan lagi.
\end{abstract}

Kata kunci: Media Sosial, Riset Visual, Mesin Crawler, Infrastruktur Big Data

\begin{abstract}
Social media gives us a huge number of data to be analyzed and sends us useful knowledge. In this paper, we develop a crawler machine for Instagram and Pinterest as an infrastructure of social media based visual research. We conduct the visual research to design product package for consumers from the middle class and upper class. The crawler machine is developed using Apache Kafka, Apache Spark, and Apache MesOS The evaluation result shows us that Apache MesOS can speed up data processing from 30 hours to one hour. In term of data selection, this machine can achieve 100\% accuracy on Pinterest. Meanwhile, on Instagram, the precision is unstable between $34.8 \%$ to $90.0 \%$. On the other hand, the recall and the accuracy on Instagram are consistently below $70 \%$. Based on the evaluation result, we conclude that the machine performs well in term of time efficiency. However, we need to improve the selection algorithm so that the precision, the recall and the accuracy on Instagram can be increased.
\end{abstract}

Keywords: Social Media, Visual Research, Crawler Machine, Big Data Infrastructure 
Sa'dyah, dkk

\section{PENDAhuluan}

\subsection{Latar Belakang Masalah}

Persaingan popularitas merek (brand) menjadi salah satu penentu apakah sebuah produk dapat bersaing di pasar. Untuk dapat berkompetisi dengan kompetitor, produsen selalu mencoba memberikan hal baru pada produk mereka. Dalam persaingan pasar, konsumen bukan hanya mempertimbangkan aspek kualitas produk, melainkan juga kesan pertama pada kemasannya. Merek yang baik biasanya memahami fungsi kemasan dalam menyampaikan pesan yang diusung oleh produk. Seperti yang disebutkan oleh Rundh (Rundh, 2009) bahwa kemasan produk berhubungan dengan variabel lain dalam pemasaran. Kemasan dan desain kemasan menjadi salah satu faktor penentu sebuah produk diminati atau tidak oleh pasar.

Pada perkembangannya, kemasan produk memberikan daya tarik pada konsumen agar membeli sebuah produk. Pada abad ke 21, kecenderungan konsumen untuk membeli barang tidak hanya berdasarkan kebutuhan (Pine \& Gilmore, 2011). Perilaku konsumen telah mengalami pergeseran dimana mereka membeli produk dengan mempertimbangkan aspek immaterial seperti emosi, hiburan dan fantasi. Dalam teori marketing tradisional, kemasan merupakan salah satu variable keputusan penting dalam menentukan pembelian (Pickton \& Broderick, 2005) (Kotler \& Keller, 2011). Dalam kemasan, hal terbesar yang menjadi pendorong konsumen untuk dapat tertarik kepada sebuah produk salah satunya adalah pada desain atau ilustrasi yang menerangkan produk yang dijual. Dalam beberapa penelitian sebelumnya, disebutkan bahwa visual influence terbukti mempengaruhi keputusan pembelian suatu barang (Clement, Kristensen, \& Gronhaug, 2013).

Dalam disiplin ilmu Desain Komunikasi Visual, desain kemasan dikerjakan melalui metode riset visual. Riset visual memiliki tiga aspek yaitu imaji, pembuat dan pemirsa. Aspek imaji merujuk pada karya visual yang sedang diteliti yaitu kemasan yang sedang dirancang. Aspek pembuat merujuk pada pembuat karya visual yaitu desainer kemasan. Sedangkan aspek pemirsa merujuk pada penikmat karya visual atau konsumen produk (Sowardikoen, 2013).

Sebuah karya visual tidak terlepas dari persepsi pemirsa terhadap karya tersebut. Oleh karena itu, untuk menghasilkan kemasan yang sesuai dengan selera dan kebutuhan konsumen (sebagai pemirsa), desainer kemasan harus melakukan penggalian informasi tentang konsumen. Pada umumnya, penggalian informasi tentang selera konsumen dilakukan melalui Focus Group Discussion, wawancara, atau pembagian kuesioner. Namun, perkembangan teknologi memungkinkan para desainer untuk menggunakan teknik baru dalam menggali informasi.

Tren saat ini menunjukkan banyak penduduk Indonesia yang menggunakan media sosial. Hal memberikan kita bonus berupa data dalam jumlah besar. Kementrian Komunikasi dan Informasi (Kominfo) merilis laporan bahwa jumlah pengguna internet (warganet) di Indonesia saat ini mencapai 63 juta jiwa dimana 95\% di antaranya menggunakan internet untuk mengakses media sosial (Kominfo, 2017). Jika setiap pengguna media sosial mengunggah status satu kali per hari, maka setiap harinya kita akan mendapatkan 59 juta rekaman baru. Faktanya, hampir setiap warganet di Indonesia memiliki lebih dari satu akun media sosial. Artinya, data baru yang diperoleh setiap harinya diperkirakan lebih dari 59 juta rekaman. Kondisi 
tersebut memungkinkan penggalian informasi tentang pemirsa dilakukan melalui media sosial.

Saat ini, terdapat dua media sosial yang dapat dieksplorasi untuk kebutuhan riset visual yaitu Instagram dan Pinterest. Instagram merupakan media sosial yang digunakan untuk berbagi foto. Pada perkembangannya, Instagram juga digunakan sebagai media promosi produk. Implikasinya, kita dapat mengamati interaksi antar pengguna yang membahas produk-produk tertentu. Dari sini, kita dapat mengamati perilaku dan persepsi mereka terhadap sebuah produk.

Adapun Pinterest merupakan media sosial yang banyak digunakan untuk mengunggah karya visual. Unggahan di Pinterest tidak langsung berkaitan dengan konsumen. Namun, dengan banyaknya desainer grafis yang mengunggah karyanya di sana, kita dapat mengambil informasi tentang tren desain grafis pada tahun tertentu melalui Pinterest.

Dalam penelitian ini, kami membangun mesin crawler pada media sosial Instagram dan Pinterest. Pembuatan mesin crawler ini ditujukan untuk memenuhi kebutuhan desainer kemasan dalam menggali informasi tentang konsumen. Terdapat dua tantangan yang harus ditempuh jika kita ingin mengembangkan perangkat lunak untuk menggali informasi pada media sosial (Zafarani, Abbasi, \& Huan, 2014). Tantangan pertama adalah pengembangan teknik pemilihan sampel yang tepat. Data di media sosial terus bertambah dalam hitungan detik. Variasi dan deviasinya hampir tidak terukur sehingga kita akan kesulitan untuk menemukan titik sampel yang tepat. Dalam penelitian ini, penyelesaian untuk permasalahan tersebut dimulai dengan mengumpulkan data pengguna media sosial sesuai dengan segmen konsumen yang dituju. Adapun pengumpulan data tentang pengguna media sosial dilakukan menggunakan algoritma Rule Based Classifier.

Tantangan kedua adalah pengembangan infrastruktur yang memadai untuk mengelola data. Proses pengumpulan data pengguna media sosial dilakukan melalui Application Programming Interface (API). API menyediakan perintah untuk mengambil data yang dibutuhkan oleh pengguna. Namun, untuk mengumpulkan data yang sesuai kriteria, kita membutuhkan teknik komputasi yang kompleks. Selain itu, data di media sosial juga bertambah dengan cepat dan berukuran besar. Oleh karena itu, kita tidak dapat memproses data media sosial dalam komputer single node. Pada penelitian ini, kami menyelesaikan permasalahan tersebut dengan komputasi terdistribusi yang dibangun dengan Apache MesOS.

Makalah ini dibagi menjadi lima bagian. Bagian pertama menjelaskan tentang pendahuluan. Bagian kedua landasan teori yang mendasari penelitian ini. Bagian ketiga menjelaskan tentang penggunaan algoritma Rule Based Classifier serta arsitektur mesin crawler. Bagian keempat menjelaskan tentang uji coba dan evaluasi. Bagian kelima menjelaskan tentang kesimpulan. 


\subsection{Rumusan Masalah}

Terdapat dua permasalahan yang harus diselesaikan dalam penelitian ini. Permasalahan pertama adalah algoritma seperti apa yang harus digunakan agar mesin crawler dapat mengumpulkan data dari segmen konsumen yang dituju. Permasalahan kedua adalah bagaimana merancang arsitektur mesin crawler untuk menggali data dari Instagram dan Pinterest dengan mempertimbangkan ukuran dan kecepatan penambahan data.

\subsection{Tujuan Penelitian}

Adapun tujuan penelitian yang akan dicapai adalah dihasilkannya mesin crawler pada Instagram dan Pinterest yang dapat mengunduh data dengan cepat sesuai dengan kriteria data yang ditentukan.

\subsection{Ruang Lingkup Penelitian}

Ruang lingkup penelitian ini meliputi penentuan algoritma klasifikasi untuk mendapatkan data yang dibutuhkan serta perancangan arsitektur mesin crawler yang dapat memfasilitasi pengambilan data dalam jumlah banyak dan dalam waktu yang cepat. Adapun data rujukan untuk produk yang biasa digunakan oleh konsumen menengah ke atas telah disediakan sebelumnya oleh desainer kemasan.

\section{LANDASAN TEORI}

Dalam penelitian ini akan dibuat mesin crawler untuk memenuhi kebutuhan riset visual dalam menggali selera konsumen. Oleh karena itu, dibutuhkan landasan teori untuk memahami studi kasus yang dikerjakan serta mengetahui infrastruktur yang akan digunakan. Landasan teori di Bab 2 ini terdiri dari empat bagian yaitu Riset Visual, Application Programming Interface (API), infrastruktur Big Data dan algoritma Rule Based Classifier.

\subsection{Riset Visual dan Elemen Kemasan}

Kemasan produk memiliki enam fungsi. Fungsi tersebut antara lain fungsi proteksi, fungsi pengelompokan, penempatan dan penyimpanan, keamanan, fungsi informasi, fungsi kemudahan fisik dan fungsi marketing (Kusrianto, 2007). Sementara itu, dalam riset visual, kita mengenal tiga aspek yaitu aspek imaji, aspek pemirsa dan aspek pembuat. Kemasan yang baik harus memiliki aspek imaji yang memenuhi selera aspek pemirsa serta memenuhi 6 fungsi yang telah disebutkan

Untuk mendukung keenam fungsi yang telah disebutkan Adi Kusrianto, terdapat lima elemen yang harus dipertimbangkan dalam perancangan kemasan (Vyas, 2015). Kelima elemen tersebut adalah nama brand, bahan kemasan, bentuk kemasan, informasi produk dan elemen grafis (kombinasi warna, tata letak dan ukuran). Aspek Imaji dari kemasan dibentuk oleh kombinasi dari lima elemen kemasan ini. Oleh karena itu dibutuhkan informasi yang memadai tentang bagaimana kombinasi elemen kemasan yang memenuhi selera aspek pemirsa. Dalam riset visual ini, aspek pemirsa adalah kalangan menengah ke atas. 
Sebelum membuat mesin crawler, penting bagi kita untuk mendefinisikan bagaimana ciri konsumen menengah atas di media sosial. Berdasarkan ciri tersebut, mesin crawler akan mengambil data di media sosial. Dengan data tersebut, kita dapat memperhatikan perilaku segmen konsumen yang dituju. Pada umumnya, segmentasi konsumen dibagi berdasarkan jumlah pengeluaran mereka setiap bulan. Namun dalam riset menggunakan media sosial, kita tidak mungkin mendapatkan data tersebut. Oleh karena itu, dalam penelitian ini, pembagian segmentasi konsumen dilakukan berdasarkan produk yang mereka konsumsi dan dibagikan melalui media sosial.

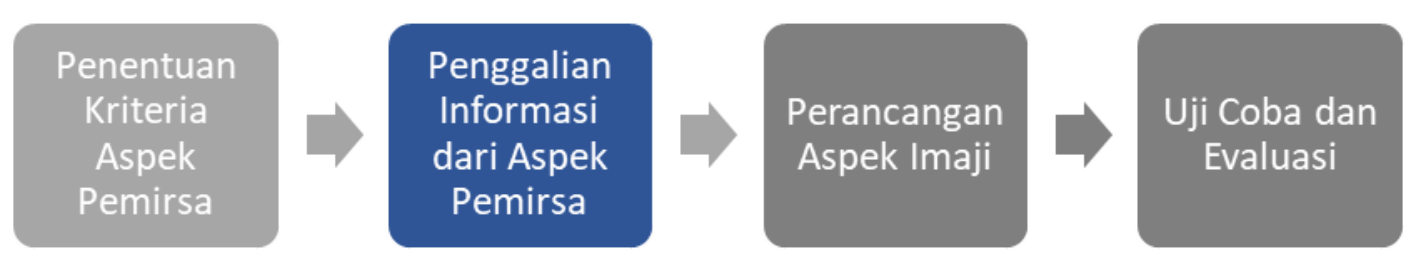

Gambar 1. Metodologi Riset Visual

Dalam penelitian ini, data yang dihasilkan oleh mesin crawler akan digunakan sebagai bahan riset visual untuk mempertimbangkan kombinasi elemen kemasan yang baik dan dapat diterima oleh konsumen. Secara umum, metodologi riset visual dapat dilihat pada Gambar 1. Pada gambar tersebut, terdapat empat langkah yang harus ditempuh mulai dari penentuan kriteria aspek pemirsa hingga uji coba dan evaluasi. Penelitian yang ada pada makalah ini berfokus pada langkah kedua yaitu penggalian informasi dari aspek pemirsa.

Pada umumnya, penggalian informasi tentang perilaku pemirsa digali melalui kuesioner, Focus Group Discussion, atau wawancara. Namun dalam penelitian ini, penggalian informasi dilakukan dengan pendekatan lain. Desainer kemasan akan terlebih dahulu mengumpulkan data berupa kumpulan username dari pengguna Instagram yang termasuk segmen konsumen menengah ke atas. Selain itu, desainer kemasan juga mengumpulkan tren desain untuk makanan melalui Pinterest. Penelitian ini dilakukan untuk mendukung otomatisasi pengumpulan data tersebut.

\subsection{API pada Instagram dan Pinterest}

Pada penelitian ini, kita menggunakan Instagram dan Pinterest sebagai sumber data. Instagram merupakan media sosial yang memfasilitasi penggunanya untuk menunggah foto. Instagram memiliki dua fitur utama yaitu unggah foto di halaman utama dan unggah foto di Instagram Story. Saat ini, Instagram banyak digunakan untuk keperluan jual-beli, branding dan periklanan.

Adapun Pinterest merupakan media sosial yang juga memfasilitasi penggunanya untuk mengunggah foto. Namun segmen pengguna Pinterest berbeda dengan Instagram. Pinterest banyak digunakan untuk menyimpan portofolio foto ataupun desain grafis. Oleh karena itu, Pinterest sering digunakan sebagai rujukan untuk mencari inspirasi desain oleh para desainer grafis. Pinterest menyebut setiap gambar yang diunggah sebagai Pin. Pin ini dapat dikumpulkan ke dalam suatu album yang disebut dengan Board. Pada umumnya, pengguna Pinterest mengumpulkan Pin dengan topik-topik yang sama ke dalam suatu Board. 
Untuk mengumpulkan data dari Pinterest dan Instagram, kita menggunakan API. API (Application Programming Interface) merupakan sebuah teknologi yang memungkinkan dua buah aplikasi atau lebih untuk bertukar data tanpa memberikan akses bagi pengguna ke dalam tempat penyimpanan data secara langsung. Instagram dan Pinterest merupakan aplikasi media sosial yang menyediakan API agar kita dapat mengakses data dengan mudah.

Untuk menggunakan API pada masing-masing media sosial, kita dapat menggunakan format request tertentu. Format request data pada API di media sosial Instagram dapat diakses pada halaman web https://www.instagram.com/developer/. Sedangkan format request data pada API di media sosial Pinterest dapat diakses pada halaman web https://developers.pinterest.com/

\subsection{Infrastruktur Big Data}

Infrastruktur teknologi adalah hal paling mendasar yang harus terkondisikan dengan baik pada penelitian di bidang Big Data. Pada bidang ini, pekerjaan yang harus dilakukan pada umumnya berhubungan dengan penyimpanan, streaming dan analisa data. Dalam beberapa dekade, pengelolaan data bergantung pada basis data relasional. Namun, pada kasus Big Data, data yang dikelola memiliki kecepatan, volume dan variasi yang sangat besar. Oleh karena itu, basis data relasional tidak lagi mampu untuk mendukung pemrosesan data yang sudah memenuhi kriteria Big Data.

Terdapat beberapa infrastruktur yang harus disiapkan saat kita ingin mengelola Big Data. Pertama adalah infrastruktur yang menangani aliran data pada Big Data yang mengalir secara cepat dan real time. Kedua adalah infrastruktur yang menangani penyimpanan data sehingga mudah dikelola. Data pada Big Data memiliki banyak variasi. Ada yang terstruktur dan ada yang tidak. Selain itu, data yang disimpan juga berukuran besar. Oleh karena itu, dibutuhkan infrastruktur yang mampu mengatasi hal ini. Ketiga adalah infrastruktur untuk melakukan analisa data. Dan keempat adalah infrastruktur yang menangani pemrosesan data secara terdistribusi. Data pada Big Data berukuran besar sehingga membutuhkan waktu yang lama untuk diproses. Adanya pemrosesan terdistribusi memungkinkan kita untuk mempersingkat waktu pengolahan.

Pada penelitian ini, infrastruktur untuk menangani aliran data dibangun dengan menggunakan Apache Kafka. Apache Kafka merupakan platform untuk streaming dengan latensi rendah dan throughput tinggi. Apache Kafka biasa digunakan untuk mengumpulkan aliran data secara realtime serta dibangun dalam bahasa pemrograman Scala dan Java.

Apache Kafka bekerja dengan sistem publish/subscribe messaging. Dalam sistem ini dikenal istilah Producer, Broker dan Consumer. Producer merupakan suatu sistem yang mengambil data untuk topok tertentu secara real-time. Kemudian, topik tersebut didistribusikan kepada Consumer melalui Broker. Consumer merupakan sebuah sistem yang membutuhkan data untuk dikelola. Sebuah sistem pengolahan data dapat memiliki lebih dari satu Consumer dan Producer. 
Untuk pengelolaan data dalam skala besar dengan menggunakan algoritma machine learning, kita dapat menggunakan Apache Spark. Apache Spark merupakan framework yang dapat melakukan analisa pada data dalam skala besar dan bersifat opensource. Untuk mendukung analisa data, Apache Spark dapat menampilkan banyak pilihan model visualisasi data.

Untuk mendukung kinerja Apache Kafka dan Apache Spark, kita dapat menggunakan Apache MesOS. Apache MesOS merupakan cluster manager yang memungkinkan kita untuk mengelola data secara terdistribusi.

\subsection{Algoritma Rule Based Classifier.}

Rule based classifier adalah algoritma klasifikasi yang menggunakan sekumpulan aturan IF-THEN untuk melakukan prediksi kelas pada suatu data. Secara sederhana, kita dapat mengekspresikan Rule based classifier dengan pseudocode di bawah ini:

IF kondisi THEN kesimpulan

bawah ini:

Contoh penggunaan Rule Based Classifier dapat dilihat pada rule R1 di

Rule 1

IF usia < 20 AND mahasiswa = yes THEN return yes;

Pada Rule based classifier terdapat prekondisi yang diwakilkan dengan pernyataan setelah IF, dan konsekuensi yang diwakilkan oleh pernyataan setelah THEN. Prekondisi dapat memiliki lebih dari satu syarat. Sementara konsekuensi berisi prediksi kelas dari data yang sedang diuji. Pada penelitian ini, Rule Based Classifier digunakan untuk menyeleksi data mana yang dibutuhkan oleh desainer kemasan dan data mana yang tidak dibutuhkan oleh desainer kemasan

\section{METODOLOGI PENELITIAN}

Metodologi yang digunakan dalam penelitian ini dapat dilihat pada Gambar 2. Metodologi tersebut terdiri dari empat tahap yaitu analisa kebutuhan, desain perangkat lunak, implementasi perangkat lunak serta uji coba dan evaluasi. Adapun penjelasan yang lebih rinci untuk setiap langkah dapat dilihat pada Subbab 3.1, dan

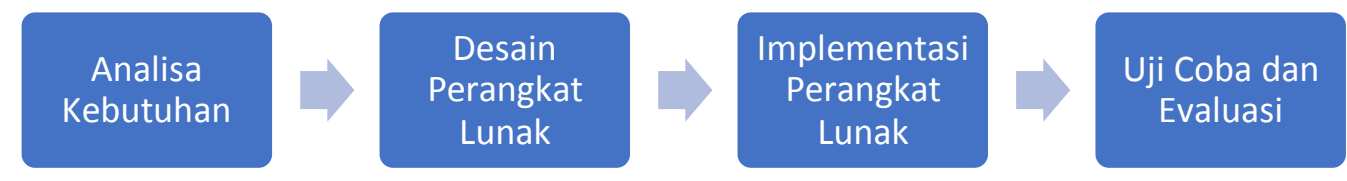

Subbab 3.2.

Gambar 2 Metodologi Pembuatan Perangkat Lunak

\subsection{Analisa Kebutuhan}

Mesin Crawler pada penelitian ini digunakan untuk mengambil data di media sosial sesuai dengan kriteria yang ditentukan oleh pengguna (desainer kemasan). Untuk 
menjalankan tugas tersebut, mesin crawler setidaknya harus mampu melakukan dua hal yaitu mengunduh data serta menyeleksi data yang akan diunduh.

Data yang dikumpulkan oleh mesin crawler pada penelitian ini berasal dari dua media sosial yaitu Instagram dan Pinterest. Dari Pinterest, kita membutuhkan informasi terkait tren elemen grafis (tipografi, warna, bentuk dan ukuran). Untuk mendapatkan informasi tentang tipografi, ukuran dan bentuk, kita menggunakan data Note, Attribution dan Image. Sedangkan untuk mendapatkan tren warna, kita menggunakan data Color. Tabel 1 menunjukkan penjelasan lebih rinci tentang data yang akan diambil dari Pinterest.

Selain Pinterest, sumber data yang digunakan dalam penelitian ini adalah Instagram. Data yang dibutuhkan di Instagram berupa username konsumen pada segmen menengah ke atas beserta data turunannya yang berupa id, caption, media_count dan followers_count. Kriteria pengguna Instagram yang termasuk segmen konsumen menengah atas telah ditentukan sebelumnya oleh desainer kemasan. Tabel 2 menunjukkan keterangan lengkap tentang data yang diambil dari Instagram

Tabel 1 Data yang Diambil dari Pinterest

\begin{tabular}{|l|l|}
\hline Data & \multicolumn{1}{|c|}{ Keterangan } \\
\hline Pin & $\begin{array}{l}\text { Pin adalah istilah yang digunakan oleh Pinterest untuk merujuk item } \\
\text { yang diunggah oleh pengguna }\end{array}$ \\
\hline Note & $\begin{array}{l}\text { Note memuat informasi tentang deskripsi dari Pin yang diunggah } \\
\text { oleh pengguna. }\end{array}$ \\
\hline Attribution & $\begin{array}{l}\text { Attribution memuat informasi tentang metadata dari Pin yang } \\
\text { meliputi informasi tentang pengunggah, judul serta tautan yang } \\
\text { menjadi sumber gambar dari Pin tersebut. }\end{array}$ \\
\hline $\begin{array}{l}\text { Imag } \\
\text { e }\end{array}$ & Image memuat data gambar yang ada dalam Pin \\
\hline Color & $\begin{array}{l}\text { Color memuat warna dominan dari gambar yang ada dalam } \\
\text { Pin }\end{array}$ \\
\hline
\end{tabular}

Tabel 2 Data yang dibutuhkan dari Instagram

\begin{tabular}{|l|l|}
\hline \multicolumn{1}{|c|}{ Data } & \multicolumn{1}{c|}{ Keterangan } \\
\hline Username & $\begin{array}{l}\text { Username adalah identitas unik bagi setiap pengguna } \\
\text { Instagram. }\end{array}$ \\
\hline Id & $\begin{array}{l}\text { Id yang digunakan dalam penelitian ini merujuk pada id } \\
\text { media. Id media memuat identitas unik bagi setiap foto } \\
\text { atau video yang diunggah oleh pengguna Instagram }\end{array}$ \\
\hline Caption & $\begin{array}{l}\text { Comments_count merujuk pada jumlah komentar bagi } \\
\text { foto yang diunggah oleh pengguna Instagram }\end{array}$ \\
\hline Media_count & $\begin{array}{l}\text { Media_count merujuk pada jumlah foto atau video yang } \\
\text { diunggah oleh pengguna Instagram }\end{array}$ \\
\hline $\begin{array}{l}\text { followers_coun } \\
\mathrm{t}\end{array}$ & $\begin{array}{l}\text { Followers_count merujuk pada jumlah follower dari } \\
\text { sebuah akun Instagram. }\end{array}$ \\
\hline
\end{tabular}


Untuk mendapatkan data yang telah disebutkan pada Tabel 1 dan Tabel 2, desainer kemasan harus mengisi input yang dibutuhkan oleh mesin crawler. Tabel 3 dan Tabel 4 menunjukkan input dan output dari mesin crawler yang akan dibuat.

Tabel 3 Skenario Input dan Output pada Pinterest

\begin{tabular}{|c|c|}
\hline Input & \multicolumn{1}{c|}{ Output } \\
\hline Username & Pin, Note, Atribution, Image, Color \\
\hline
\end{tabular}

Tabel 4 Skenario Input dan Output pada Instagram

\begin{tabular}{|l|l|}
\hline \multicolumn{1}{|c|}{ Input } & \multicolumn{1}{c|}{ Output } \\
\hline Username & $\begin{array}{l}\text { Daftar username follower dari username pengguna } \\
\text { yang diinputkan dimana follower tersebut termasuk } \\
\text { segmen konsumen kelas menengah atas. }\end{array}$ \\
\hline
\end{tabular}

\subsection{Desain Arsitektur dan Implementasi Perangkat Lunak}

Berdasarkan analisa kebutuhan pada Subab 3.1, kami mengembangkan algoritma dan arsitektur perangkat lunak yang bekerja di mesin crawler. Untuk membedakan segmen konsumen kelas menengah atas dengan segmen konsumen lain, desainer kemasan memberikan informasi berupa daftar produk yang biasa dikonsumsi oleh segmen menengah ke atas. Informasi ini nantinya digunakan sebagai bahan pertimbangan dalam melakukan seleksi data di Instagram. Proses seleksi data yang dikembangkan dalam penelitian ini dapat dibaca pada Subbab 3.2.1. dan Subbab 3.2.2. Adapun arsitektur mesin yang digunakan untuk mengambil data dan melakukan proses seleksi pada data tersebut dapat dilihat pada Subbab 3.2.3

\subsubsection{Algoritma Rule Based Classifier pada Instagram}

Untuk mendeteksi pengguna Instagram yang termasuk segmen kelas menengah ke atas, mesin crawler menggunakan algoritma Rule Based Classifier. Algoritma ini dilakukan dengan menyeleksi pengguna Instagram berdasarkan foto yang mereka unggah. Dalam foto yang ada di Instagram terdapat atribut caption. Desainer kemasan akan memberikan daftar nama produk yang biasa dikonsumsi oleh konsumen menengah ke atas. Sementara mesin crawler akan mengecek apakah caption dari foto yang diunggah pengguna Instagram memuat merk produk yang ada dalam daftar. Jika iya, maka mesin crawler akan mencatat username dari pengguna tersebut.

Skenario deteksi dimulai dengan memasukkan sebuah username dari pengguna Instagram. Selanjutnya, mesin crawler tersebut akan memeriksa satu persatu follower dari akun tersebut. Jika follower dari akun tersebut termasuk konsumen menengah atas, maka mesin crawler akan menyimpan username dari follower tersebut. Berikut ini pseudocode dari algoritma Rule Based Classifier untuk Instagram:

function: rule_based_classifier_Instagram (string username) segmen_menengah_atas[follower_count]; for $i=1$ to $i=$ follower_count 


$$
\begin{aligned}
& \text { if (follower[i] == private account) then } \\
& \text { go to next follower; } \\
& \text { segmen_menengah_atas [follower] = 0; }
\end{aligned}
$$

else

$$
\begin{aligned}
& \text { for } j=1 \text { to } j=\text { follower[i].media_count } \\
& \text { caption = get follower[i].media[j].caption; } \\
& \text { if (captionCheck(caption)==1) then } \\
& \text { count++; } \\
& \text { Go to next media; } \\
& \text { end if } \quad
\end{aligned}
$$

end for

if (count/follower[i].media_count $>=0.2$ ) then segmen_menengah_atas [follower] = 1; Save username follower;

else end if

end if

end for

\section{end function}

Pada pseudocode di atas, terdapat fungsi CaptionCheck(). CaptionCheck() adalah sebuah fungsi boolean yang digunakan untuk mengecek apakah di dalam caption terdapat merk produk yang biasa dikonsumsi oleh konsumen menengah ke atas. Nilai 1 mewakili kondisi dimana caption yang diperiksa mengandung merk produk untuk konsumen menengah ke atas sementara nilai 0 mewakili kondisi yang sebaliknya.

\subsubsection{Algoritma Rule Based Classifier pada Pinterest}

Untuk mendeteksi Pin yang memuat informasi tentang kemasan, desainer kemasan akan menyiapkan kata kunci yang umumnya ada pada Notes dari Pin yang membahas tentang desain kemasan. Selanjutnya, mesin crawler akan memeriksa apakah Notes dari Pin yang sedang dituju mengandung kata kunci atau tidak. Jika iya, mesin crawler akan menyimpan gambar dan attribution dari Pin yang sedang diperiksa.

Adapun skenario untuk mengumpulkan data di Pinterest dimulai dengan desainer kemasan memberikan data input berupa username dari pengguna Pinterest. Kemudian, mesin crawler akan mengunjungi Board dan Pin dari pengguna tersebut untuk diperiksa satu per satu. Di bawah ini terdapat pseudocode dari algoritma yang digunakan oleh mesin crawler di Pinterest:

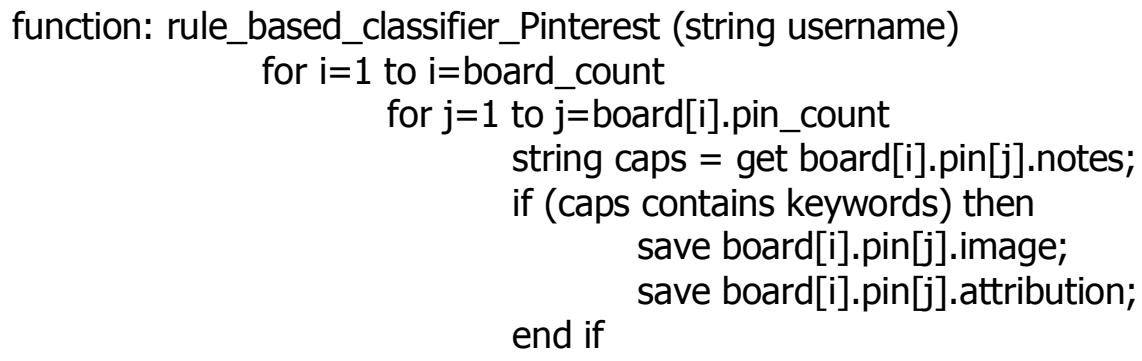


end for

end function

\subsubsection{Desain Arsitektur Mesin Crawler}

Pada penelitian ini, mesin crawler dibangun dengan memanfaatkan Apache Spark, Apache Kafka dan NodeJS. Data yang dibutuhkan diambil melalui API pada Pinterest dan Instagram. Pengelolaan streaming ditangani oleh Apache Kafka. Sedangkan proses seleksi data dan visualisasi dikelola oleh Apache Spark. Pada arsitektur tersebut, terdapat Rule Based Classifier yang tersambung dengan API dari Instagram serta tersambung dengan basis data yang berisi merk produk untuk konsumen menengah ke atas. Gambar 3 menunjukkan desain arsitektur untuk membangun mesin crawler.

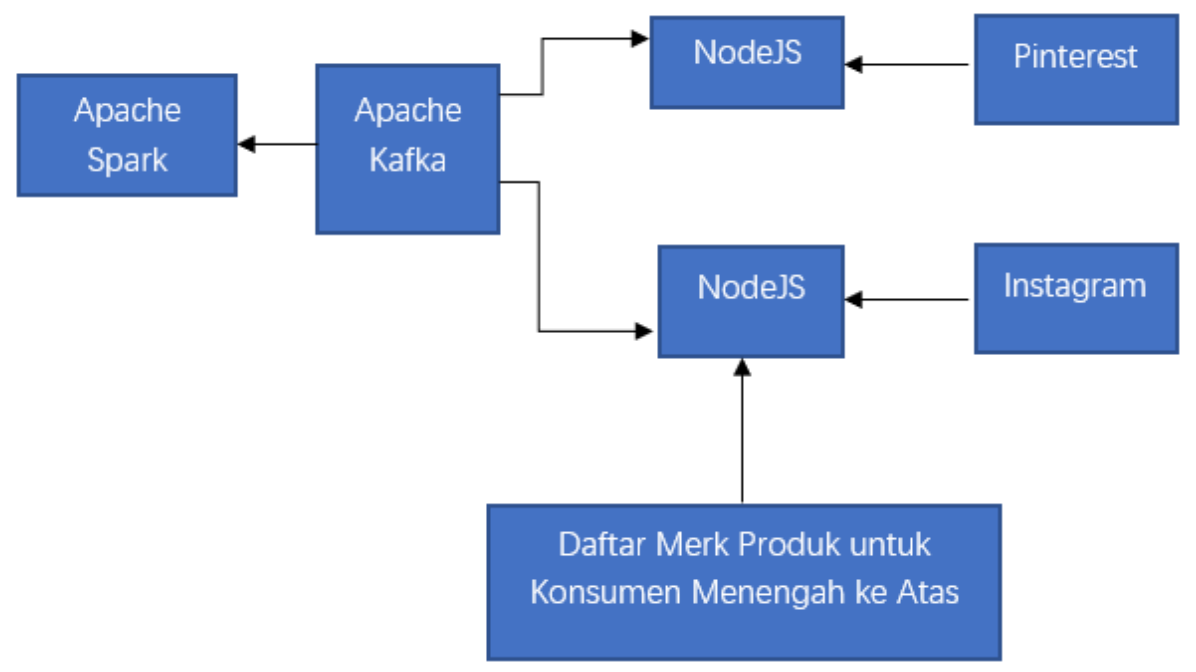

Gambar 3 Desain Arsitektur Mesin Crawler

\section{UJI COBA DAN EVALUASI}

Terdapat dua indikator untuk mengukur keberhasilan penelitian ini. Yang pertama adalah mesin crawler dapat mengumpulkan data dengan cepat. Yang kedua, data yang dikumpulkan oleh mesin crawler sesuai dengan kebutuhan pengguna. Kesesuian ini diukur dengan akurasi, presisi dan recall.

Untuk mengetahui apakah mesin crawler dalam penelitian ini memenuhi indikator keberhasilan atau tidak, kami menjalankan pengujian dalam dua skenario. Pada skenario pertama, kami menggunakan komputer Single Node yang ada pada Table 5. Adapun pada skenario kedua, kami menggunakan komputer Multi Node yang terdapat pada Tabel 6. 
Tabel 5 Spesifikasi Komputer untuk Uji Coba dengan Skenario Single Node

\begin{tabular}{|l|l|}
\hline Perangkat Keras & Perangkat Lunak \\
\hline CPU: 8 Core, Memory : 8GB & $\begin{array}{l}\text { CentOS 7 Server, Apache Kafka, } \\
\text { Apache Spark, NodeJS, Scala, JDK 1.8 }\end{array}$ \\
\hline
\end{tabular}

\section{Tabel 6 Spesifikasi Komputer untuk Uji Coba dengan Skenario Multi Node}

\begin{tabular}{|l|l|}
\hline Perangkat Keras & Perangkat Lunak \\
\hline MesOS Master (1 komputer) & CentOS 7 Server, Apache Kafka, Apache \\
CPU : 8 Core & Spark, Apache MesOS, HDFS, Scala, \\
Memory : $8 \mathrm{~GB}$ & NodeJS, JDK 1.8 \\
& \\
MesOS Agent (5 komputer) & \\
CPU : 5 x 8 Core & \\
Memory $: 18$ GB $\times 5$ & \\
\hline
\end{tabular}

Skenario pengujian ini diterapkan pada 5 akun Instagram dan 5 akun Pinterest. Akun Instagram pertama hingga kelima masing-masing memiliki jumlah follower sebanyak 73.600, 366.900, 49.500, 13.000 dan 1.032.049. Sedangkan akun Pinterest pertama hingga kelima memiliki Pin masing-masing sejumlah 936, 6.129, 10.040, 75.171, dan 125.000. Tabel 7 menunjukkan akurasi, presisi dan recall yang didapatkan selama menjalani uji coba. Sedangkan Tabel 8 menunjukkan waktu eksekusi untuk masingmasing skenario.

Tabel 7 Presisi, Recall dan Akurasi pada Mesin Crawler

\begin{tabular}{|l|l|l|l|}
\hline & Presisi (\%) & Recall (\%) & $\begin{array}{l}\text { Akurasi } \\
(\%)\end{array}$ \\
\hline Akun Instagram 1 & 71.4 & 45.5 & 60 \\
\hline Akun Instagram 2 & 88.9 & 47 & 50 \\
\hline Akun Instagram 3 & 71.6 & 52 & 50 \\
\hline Akun Instagram 4 & 34.8 & 48 & 56 \\
\hline Akun Instagram 5 & 90.9 & 64 & 62 \\
\hline Akun Pinterest 1 & 100 & 100 & 100 \\
\hline Akun Pinterest 2 & 100 & 100 & 100 \\
\hline Akun Pinterest 3 & 100 & 100 & 100 \\
\hline Akun Pinterest 4 & 100 & 100 & 100 \\
\hline Akun Pinterest 5 & 100 & 100 & 100 \\
\hline
\end{tabular}

Tabel 8 Waktu Eksekusi Mesin Crawler pada Saat Uji Coba

\begin{tabular}{|l|l|l|}
\hline \multirow{2}{*}{} & \multicolumn{2}{|c|}{ Waktu Eksekusi (detik) } \\
\cline { 2 - 3 } & Single Node & Multinode \\
\hline Akun Instagram 1 & 6300 & 500 \\
\hline Akun Instagram 2 & 34300 & 3670 \\
\hline Akun Instagram 3 & 4100 & 1800 \\
\hline Akun Instagram 4 & 1400 & 480 \\
\hline Akun Instagram 5 & 110540 & 36500 \\
\hline
\end{tabular}


Rancang Bangun Mesin Crawler di Instagram dan Pinterest untuk Kebutuhan Data pada Riset Visual

\begin{tabular}{|l|l|l|}
\hline \multirow{2}{*}{} & \multicolumn{2}{|c|}{ Waktu Eksekusi (detik) } \\
\cline { 2 - 3 } & Single Node & Multinode \\
\hline Akun Pinterest 1 & 80 & 30 \\
\hline Akun Pinterest 2 & 580 & 110 \\
\hline Akun Pinterest 3 & 1100 & 230 \\
\hline Akun Pinterest 4 & 7400 & 2050 \\
\hline Akun Pinterest 5 & 13400 & 2600 \\
\hline
\end{tabular}

Pada Tabel 7, kita dapat melihat presisi mesin crawler pada Instagram tidak stabil. Nilai tertingginya menyentuh angka 90\% sedangkan nilai terendahnya hanya 34.8 $\%$. Di samping itu, nilai akurasi dan recal/mesin crawler masih di bawah $70 \%$

Pada kasus ini, tidak stabilnya nilai presisi dipengaruhi oleh nilai False Positive. Pengguna Instagram yang termasuk pada daftar False Positive adalah toko online yang semua produknya biasa dikonsumsi oleh konsumen menengah ke atas. Kriteria seleksi yang digunakan pada algoritma Rule Based dalam penelitian ini mengenali konsumen menengah ke atas dengan menetapkan batas minimal jumlah produk yang diunggah di Instagram oleh seorang pengguna. Jika jumlah gambar produk untuk segmen menengah atas yang diunggah melebihi batas minimal, maka pengguna tersebut termasuk dalam segmen konsumen menengah atas. Pada kasus toko online, semua gambar yang diunggah adalah gambar produk untuk konsumen menengah atas. Jadi dapat dipastikan bahwa semua toko online lolos dari seleksi.

Rendahnya nilai recall menunjukkan kurangnya kemampuan mesin dalam mengenali segmen konsumen menengah atas dengan tepat. Mesin ini mengenali produk untuk segmen konsumen menengah atas dengan memeriksa caption. Sementara itu, tidak semua pengguna Instagram menuliskan merek produk di caption.

Berdasarkan hasil uji coba ini, kita dapat menentukan langkah perbaikan selanjutnya. Jumlah False Positive dapat diturunkan dengan merumuskan kriteria yang layak tentang bagaimana sebuah akun pengguna Instagram dapat dikenali sebagai toko online. Sedangkan jumlah False Negative dapat diturunkan dengan mengembangkan algoritma pengenalan gambar untuk mendeteksi merk pada gambar yang diunggah oleh pengguna Instagram

Hal lain yang dapat kita lihat pada Tabel 7 adalah nilai akurasi mesin crawler pada Pinterest yang sampai $100 \%$. Tingginya nilai akurasi ini disebabkan oleh perilaku para pengguna Pinterest yang menuliskan keterangan lengkap pada gambar yang mereka unggah. Hal ini membuat mesin crawler dapat dengan mudah menemukan data yang dituju.

Pada Tabel 8, kita dapat melihat bahwa penggunaan komputer multinode berpengaruh pada waktu eksekusi mesin crawler. Akun Instagram dengan 1.032.049 follower dapat diproses dalam waktu 36500 detik atau satu jam. Dimana sebelum menggunakan komputer multi node, pengolahan untuk akun Instagram ini membutuhkan waktu lebih dari 30 jam. 


\section{KESIMPULAN}

Berdasarkan hasil uji coba yang telah dilakukan, mesin crawler yang dibangun pada penelitian ini memiliki akurasi, recall dan presisi yang masih perlu ditingkatkan lagi. Sedangkan dari sisi arsitektur perangkat lunak, kombinasi antara Apache Kafka, Apache Spark dan Apache MesOS dapat membuat proses streaming dan seleksi data berjalan dengan cepat. Adanya Apache MesOS memungkinkan pemrosesan data berjalan secara terdistribusi di banyak node. Hal ini dapat mempercepat pengolahan data secara signifikan.

\section{DAFTAR PUSTAKA}

Clement, J., Kristensen, T., \& Gronhaug, K. (2013). Understanding Consumer's InStore Visual Perception: The Influence of Package Design Features on Visual Attention. Journal of Retailing and Consumer Services, 234-239.

Graves, P. (2010). Consumerology : The Market Research Myth, The Truth about Consumers and The Psychology of Shopping. London: Nicholas Braley Publishing.

Kominfo, K. (2017, Mei 31). Kominfo : Pengguna Internet di Indonesia 63 Juta Orang. Retrieved from Kementrian Komunikasi dan Informasi: https://kominfo.go.id/index.php/content/detail/3415/Kominfo \%3A Pengguna Internet di Indonesia 63 Orang/0/berita_satker

Kotler, P., \& Keller, K. (2011). Marketing Management . New Jersey: Prentice Hall.

Kusrianto, A. (2007). Packaging Design. Majalah Concept.

Majalah Marketing. (2016, Desember). 12 Karakter Unik Konsumen Indonesia. Indonesia: Majalah Marketing.

Pickton, D., \& Broderick, A. (2005). Integrated Marketing Communication . Prentice Hall.

Pine, J., \& Gilmore, J. (2011). The Experience Economy, Update Edition. Harvard Business Press.

Rundh, B. (2009). Packaging Design: Creating Competitive Advantage with Product Packaging. British Food Journal 111 (9), 988-1002.

Sowardikoen, W. (2013). Metodologi Penelitian Visual. Bandung: Dinamika Komunika.

Vyas, H. (2015). Packaging Design Elements and Users Perception: A Context in Fashion Branding and Communication. Journal of Applied Packaging Researches Vol 7 No 2.

Zafarani, R., Abbasi, A., \& Huan, L. (2014). An Introduction To Social Media Mining. Cambridgeshire: Cambridge University Press. 